\title{
APPLICATION OF INERTIAL MEASURING UNIT IN AIR NAVIGATION FOR
} ALS AND DAP

\author{
D. A. Gura ${ }^{1 *}$, G. G. Shevchenko ${ }^{1}$, L. F. Kirilchik ${ }^{2}$, D. V. Petrenkov ${ }^{1}$, T. A. Gura ${ }^{1}$ \\ ${ }^{1}$ Kuban State Technological University, Department of Cadastre and Geological engineering, \\ Krasnodar, Moscovskaya \\ ${ }^{2}$ Don State Technical University, Rostov-on-Don
}

Published online: 15 February 2017

\begin{abstract}
This article describes the inertial measuring device IMU, as well as its use in airborne laser scanning and digital aerial photography. This device is used during the operation of a scanning unit and an aerial photo camera. The structure of an additional connection for a digital video camera is proposed, which will record video together with the GPS and IMU data stream. Also, conclusions are given about the quality of output data that affect a final product in engineering surveys.
\end{abstract}

Keywords: Inertial measuring device (IMU), accelerometer, gyroscope, magnetometer

\section{INTRODUCTION}

In modern world, you cannot do without accurate navigation and control systems. Accuracy, for stabilization and guidance purposes plays a key role in industrial, aviation and defense markets. This is an important element of inertial navigation systems in unmanned aerial vehicles, autonomous uninhabited underwater vehicles, automatically controlled train carriages, automatic ground devices, remotely controlled devices, large format cameras and various portable equipment requiring the use of compact inertial measuring devices for operation provision when it is impossible to work via GPS channels

doi: http://dx.doi.org/10.4314/jfas.v9i1s.727 


\section{INERTIAL MEASURING UNIT (IMU)}

An inertial measuring unit is an electronic device that measures and provides a certain angular velocity force to a body, and sometimes the magnetic field surrounding the body, using the combination of accelerometers and gyroscopes and magnetometers. Usually IMU are used for aircraft maneuvering, including unmanned aerial vehicles (UAVs), among many others, also space vehicles, including satellites and descent vehicles. The latest developments allow to use IMU with the support of GPS devices. IMU allows you to compensate the operation of GPS receiver at certain points, for example, when GPS signals are not available in tunnels, inside buildings or when electronic interference is present.

IMU is the main component of inertial navigation systems used in aerospace vehicles, navigational devices, unmanned aerial vehicles and guided missiles. In this case, the data collected from IMU sensors allow a computer to track the position of an aircraft in space. An example of an inertial navigation unit is shown on Fig. 1

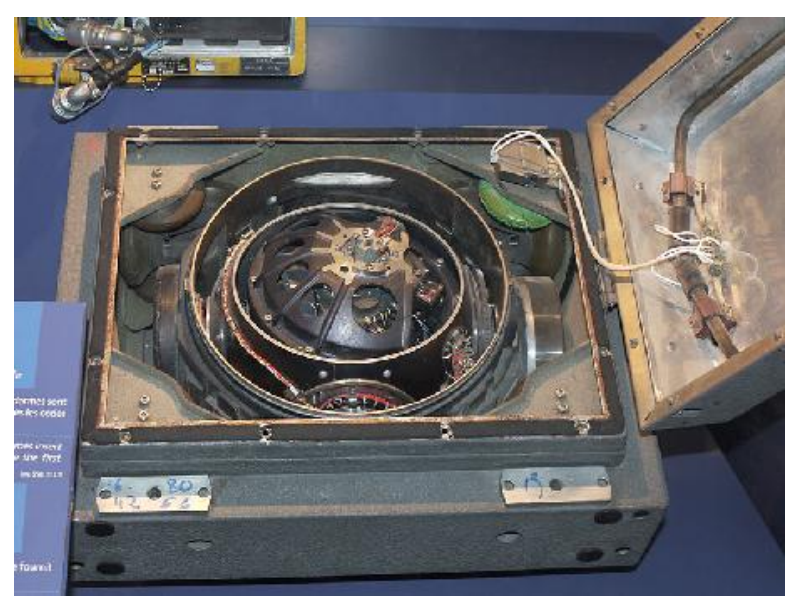

Fig.1. Inertial navigation unit

\section{OPERATION PRINCIPLE}

An inertial measuring unit (IMU) operates by the detection of current acceleration rate using one or more accelerometers, and detects the changes in rotational attributes such as pitch, roll and yaw using one or more gyroscopes. Some of them also include a magnetometer, mainly for an auxiliary calibration orientation.

Inertial navigation systems contain IMUs that have angular and linear accelerometers to measure the changes in space. Some IMUs also have a gyroscopic element to maintain an absolute angular mismatch. 
Angular accelerometers measure the way of a vehicle rotation in space. Typically, there is one sensor at least for each of three axes: pitch (nose up and down), yaw (nose to the left and to the right) and roll (clockwise or counterclockwise in the direction of travel).

Nowadays inertial guidance systems are combined usually with satellite navigation systems using a digital filtering system. An inertial system provides short-term data, while a satellite system corrects the accumulated error of an inertial system.

\section{MEASURING DEVICES}

The term IMU is widely used to refer to a casing (a box) containing three accelerometers and three gyroscopes and three magnetometers (optionally). Accelerometers (Fig. 2) are arranged in such a way that their measurement axes are in the orthogonal position from each other. They measure inertial acceleration, known as G-forces.

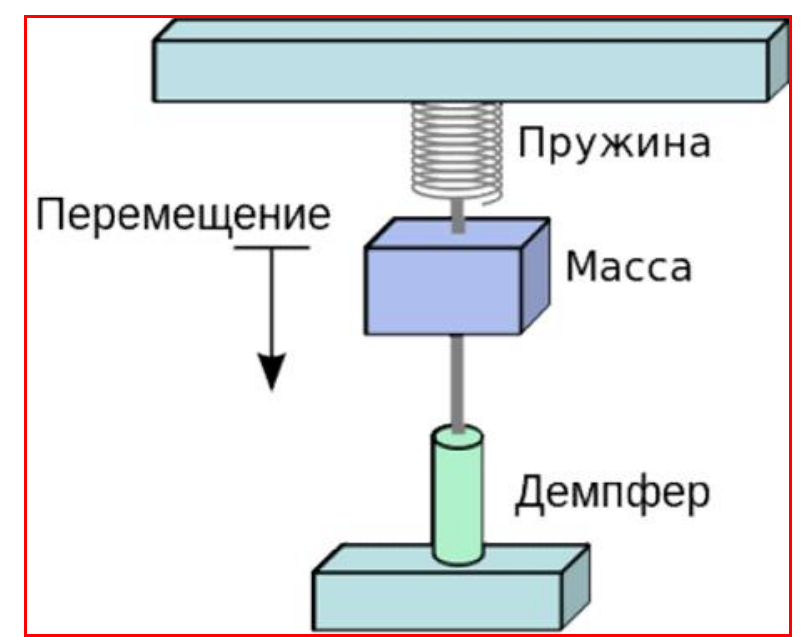

еремещение - Movement / ружин - Spring /

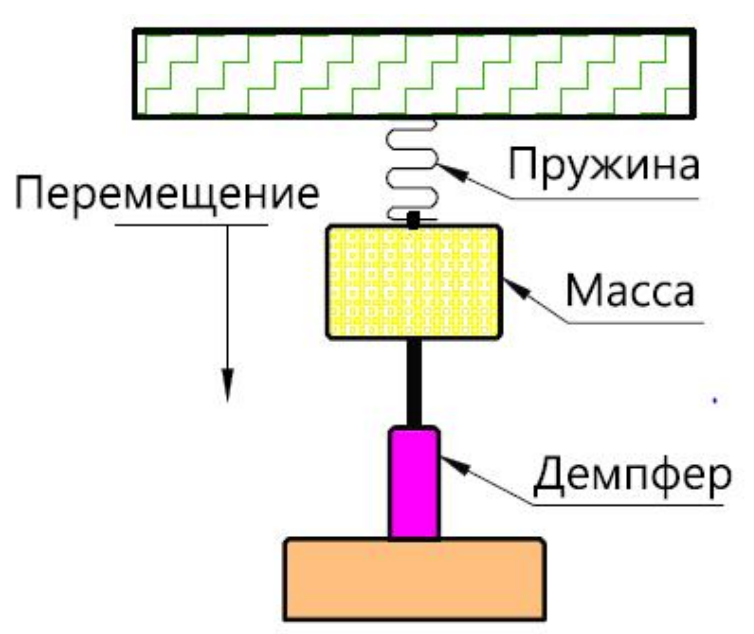

cc - Weight / емпфер - Damper

Fig.2. Accelerometer scheme

Three gyroscopes (Figure 3) are located similar to an accelerometer with the orthogonal arrangement of axes, measuring the position of rotation relative to an arbitrarily chosen coordinate system. 

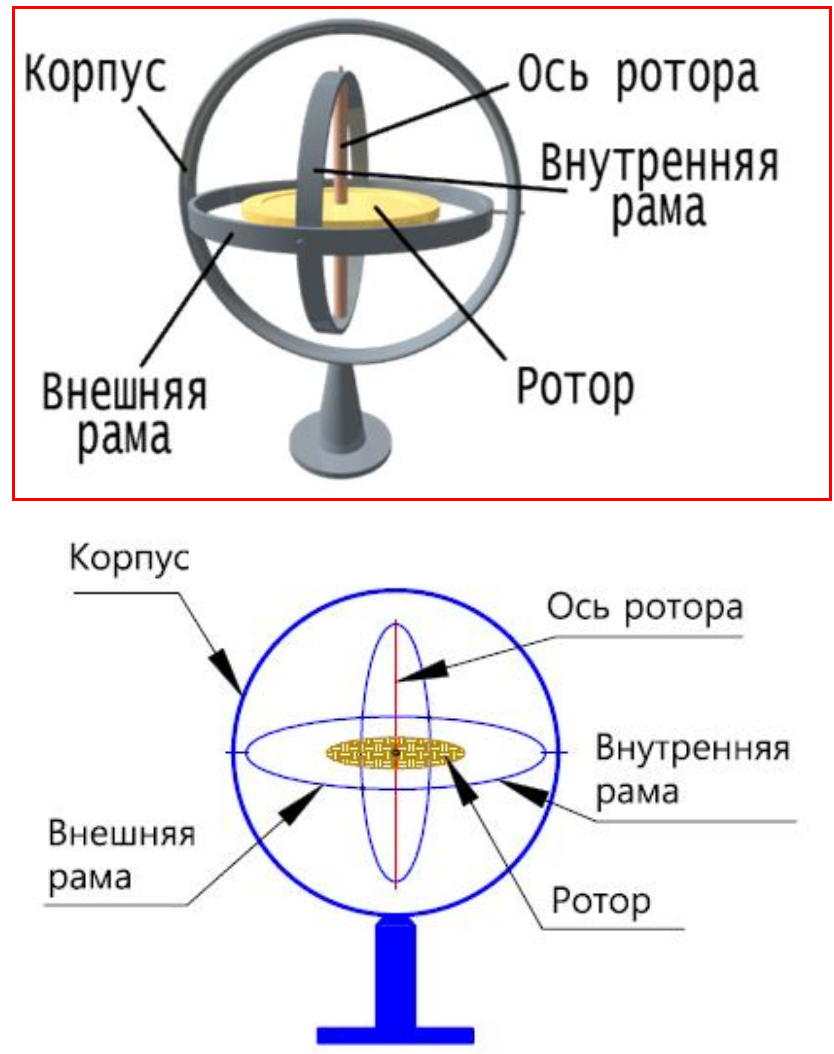

орпус-Case / сь ротор - Rotor axis / нешняя р м - Outer frame / нутренняя р м Inner frame / отор - Rotor

Fig.3. Gyroscope scheme

Recently, more and more manufacturers provide three magnetometers in an IMU. This provides better performance for dynamic orientation calculation. At the present stage, their dimensions are reduced to a minimum. Magnetometer (Fig. 4) is designed to measure the projections of induction vector concerning the Earth magnetic field, using three axes of its own coordinate system. 

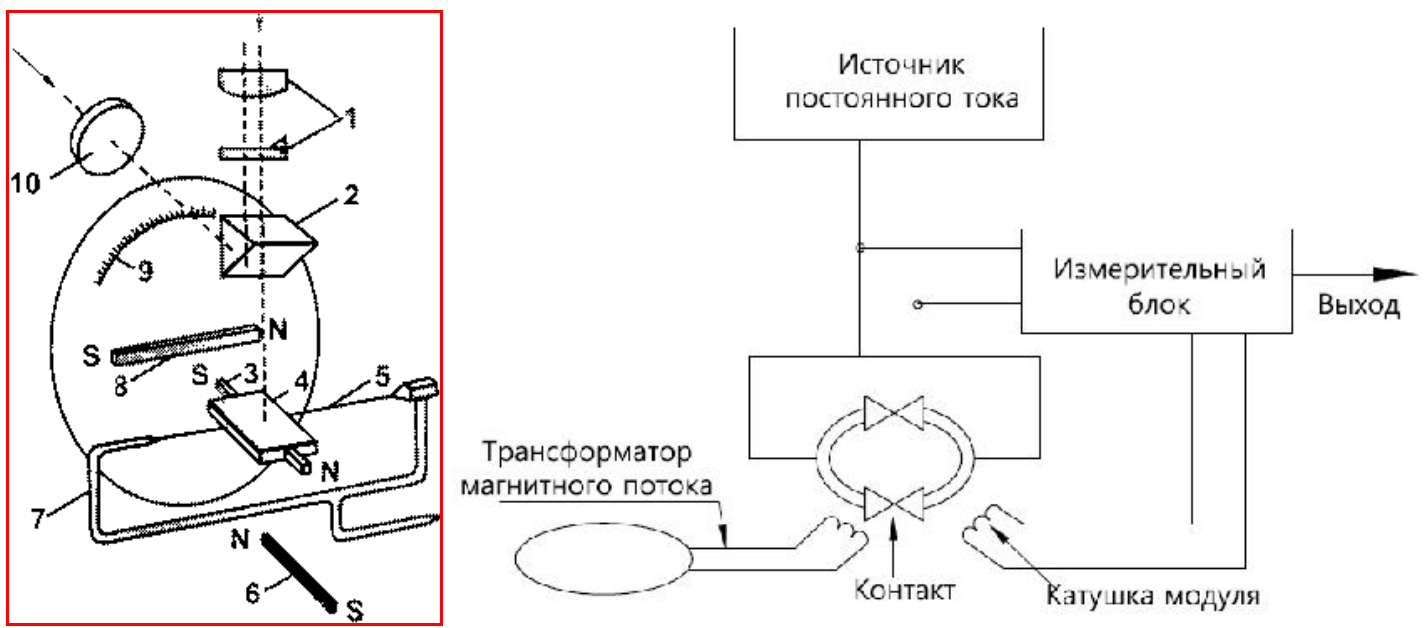

сточник постоянного ток - DC source / змерительный блок - Measuring unit / ыход

- Exit / p нсформ тор м гнитного поток - Magnetic flux transformer / онт кт - Contact / тушк модуля - Module coil

Fig.4. Quartz magnetometer scheme

\section{APPLICATION FIELDS}

IMUs are used on vehicles equipped with inertial orientation systems. They are also used only on air and space vehicles, in order to report inertial measurements to a pilot. They (IMU) are of great importance during spacecraft flights, the maneuvering of manned or unmanned aerial vehicles and other vessels.

In addition to navigational purposes, they may serve as orientation sensors in the human motion field. They are often used for sports equipment and animation applications [1].

Using orientation sensors, the term IMU is often applied as the synonym for an attitude-andheading reference system. Nevertheless, IMU is not only an attitude-and-heading reference system, but also an additional key of a differential data processing system that calculates relative orientation in space [2].

\section{USE IN AIR NAVIGATION}

In a navigation system, the data reported by IMU are sent to the computer that calculates a current position based on speed and time. In combination with a computerized map system, the guidance system can use this method to show a pilot where an aircraft is located geographically, similar to the GPS navigation system but without the relation to any external components, such as satellites. This navigation method is called the numbering (reading). An example of IMU navigation sensor is shown on Figure 5 [3]. 


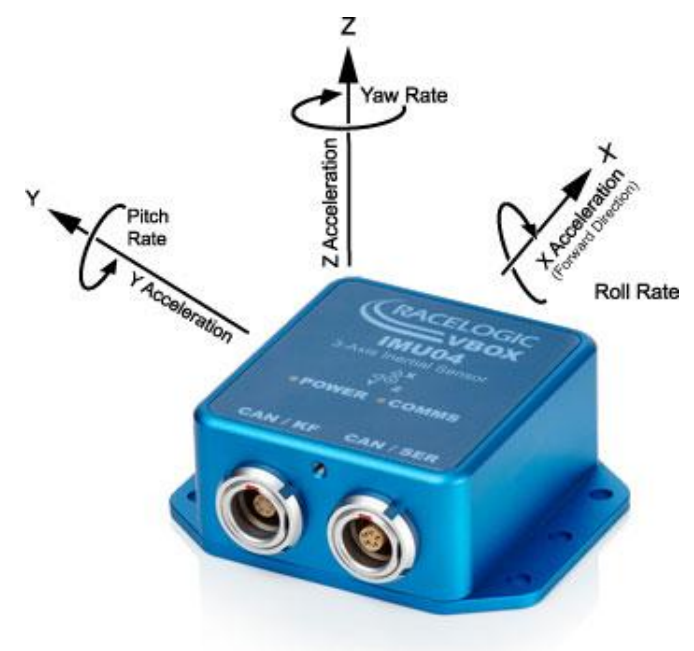

Fig.5. Example of IMU navigation sensor

\section{IMU SHORTCOMINGS FOR NAVIGATION}

The main disadvantages of IMU use for navigation are that they tend to suffer from an accumulated error, including a sinusoidal error. Since the control system constantly adds the detected changes to the previously calculated positions, any errors in the measurement accumulate from point to point. This leads to inaccuracy. Tracking systems such as GPS can be used to exclude drift errors permanently [4].

\section{ERROR SENSORS}

The behavior of a gyroscope and accelerometer sensors is often depicted using the model based on the following errors, assuming that they have an appropriate measuring range and throughput:

- bias error: this error can be divided between stability performance and repeatability;

- scale error rate: errors for first-order sensitivity;

- desynchronization error: due to the imperfection of mechanical installation;

- cross-sensitivity of an axis: non-axis measurement is induced along the axis of the sensor orthogonal axis;

- noise: depending on desired dynamic characteristics;

- sensitivity to the environment: mainly sensitivity to temperature gradients and accelerations. All these errors depend on various physical phenomena characteristic of each sensor technology. Usually, target performance is better than the absolute performance sensors for applications. However, the efficiency of the reproduction sensors has greater or lesser 
accuracy over time, and, therefore, can be evaluated and compensated in order to improve its efficiency. This is a real-time performance improvement based on both sensors and IMU models. The complexity for these models will be selected depending on the required performance, as well as on the type of an application in question.

Sensors and IMU models are factory-calibrated using calibration parameters, a multi-axis rotary platform and a climate camera. They can be calculated for each individual product or can be common to all products.

\section{IMU INSTALLATION AND PERFORMANCE}

A high IMU performance is adapted to work in harsh vibration conditions, which are extinguished by shock absorbers [5].

These shock absorbers must perform the following functions:

- Reduce the number of sensor errors due to mechanical vibrations;

- Protect sensors, as they can be damaged by shock or vibration;

- Compensate the accumulated errors in the processing during a trajectory record.

Suspended IMUs are high-performance, even when they operate in harsh environments. However, in order to achieve this productivity, it is necessary to compensate three main factors:

- Two orthogonal rotations;

- Acceleration orthogonal to rotation;

- Effects of centrifugal accelerations.

The reduction of these errors can be achieved by increasing the frequency of data processing. However, the developments of algorithms capable of these errors elimination requires a deep knowledge of an inertial system and sensors / IMU design. If a suspension allows to increase IMU performance, the side effect may depend on a unit size and weight [6], [7].

\section{IMU IN AIR NAVIGATION FOR ALS AND DAP}

At the present stage of ALS AND DAP an IMU unit is usually presented inside a scanning device, interacting with the main components of the system, namely with the laser pulse range finder. In general, this is a scanning unit - the main component of an air laser scanner. Inertial-satellite navigation systems combine inertial positioning technology, i.e. the method of movement parameters and an object coordinate detection in the absence of external landmarks or signals (the block of inertial sensors) and satellite navigation - the technology of practical application concerning GPS + G LONASS means in order to determine a location and 
a direction. These systems are necessary to ensure a continuous and an accurate determination of coordinates and the elements of object spatial orientation $[8,9]$.

An important factor is the reading of IMU data at the time of equipment installation and calibration. Using an inertial measuring device during flight-survey works, the current values of the roll, pitch and yaw angles are displayed on a monitor screen, which in its turn helps a user (a board operator) to monitor the mutual position of an aircraft in space.

Nowadays, this module is used in conjunction with two main devices: a scanning unit and a digital wide-format aerial camera. In addition, GPS is involved in this complex.

In this review, we offer the connection of a video camera to the whole aeronautical complex, which will result in a mutual synchronization scheme with IMU and GPS data stream. The interaction scheme of the main components is shown on Figure 6.

\section{CONCLUSIONS}

The above stated materials allow us to conclude that an inertial measuring unit has its pros and cons. An effective use of IMU for air laser scanning and digital aerial and video record can be achieved by combined data use of IMU module and GPS signals to compensate the errors during a flight. The interaction of three components (a scanning unit of a photo and a video camera) should correspond to the abovementioned scheme, and not otherwise, since the construction and the monitoring of industrial and other objects requires deep detailing and the representation of the model in a unified system. In other words - any point of a topographic plan should correspond to the same point in a video film [9]. 


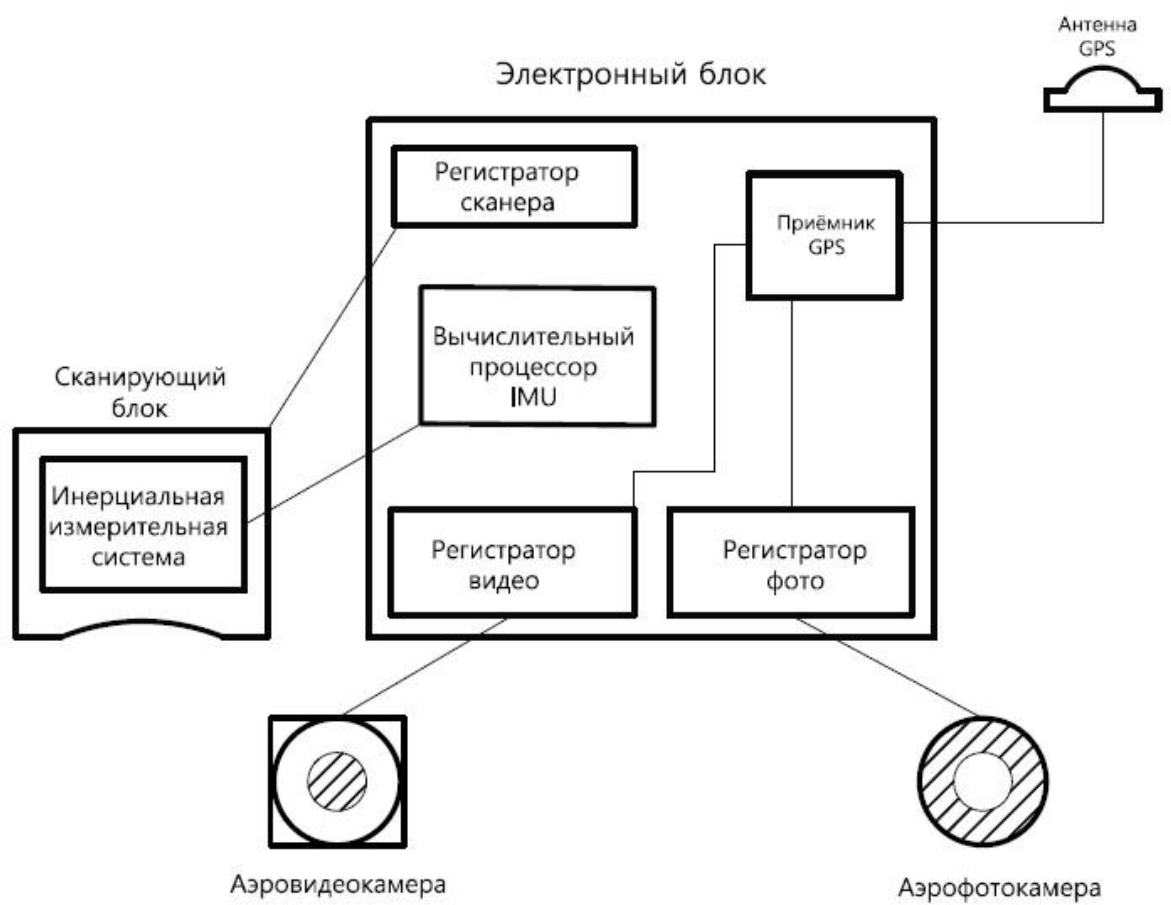

лектронный блок - electronic unit / егистр тор ск нер - Scanner recorder / риемник/ нтенн GPS - GPS Receiver / Antenna / к нирующий блок - Scanning unit / нерци льн я измерительн я систем - Inertial measuring system / ычислительный процессор IMU - IMU computing processor / егистр тор видео/фото - video / photo recorder / эровидеок мер - Aero video camera / эрофоток мер - Aerial camera

Fig.6. Example of interaction between a scanning device, a camera and a video camera

\section{SUMMARY}

Thus, the output data that passed the post processing shows the correct and precise method of IMU operation. The joint equalization of data streams provides an estimate of a flight trajectory accuracy, and a single interaction of measuring and photographic recording devices with these data allows to improve the quality of a final product (orthophotoplan, topoplan, 3D terrain model, etc.)

\section{REFERENCES}

[1] Times Connecting the Global Electronics Community. «GPS systems with IMU tracks, user opinions». [Electronic resource]: Access mode http://www.eetimes.com/document.asp?doc_id=1259727

[2] Xsens company as an innovator in 3D motion tracking technology. [Electronic resource]: Access mode - https://www.xsens.com/fascination-motion-capture/ 
[3] Robotic navigation, pilot guide. Electronic resource]: Access mode https://books.google.ru/books?id=oN0DAAAAMBAJ\&pg=PA87\&dq=1954+Popular+Mecha $\underline{\text { nics }+ \text { January \&hl=en\&sa }=X \& \text { ei }=\text { TV0mT- }}$

7WMoGftwfi4dizCg\&redir_esc=y\#v=onepage $\& \mathrm{q}=1954 \% 20 \mathrm{Popular} \% 20 \mathrm{Mechanics} \% 20 \mathrm{Janu}$ $\underline{\text { ary } \& \mathrm{f}=\text { true }}$

[4] Springer - Handbook of Robotics, p. 484. Electronic resource]: Access mode https://books.google.at/books?id=Xpgi5gSuBxsC\&pg=PA484\&lpg=PA484\&dq=imu+drit1+ епог+qu dг tic\&source=ыlots=lujmu7f67R\&sig=5вBVFhOs2NBWNhE461QafihIF98\&hl=e n\&sa $=X \& v e d=O C D Q Q 6 A E w A 20$ VChMI14eS6nLxgIVyroUCh31UgER\#v=onepage \&q=imu $\% 20 \mathrm{drift} \% 20 \mathrm{enoг \% 20qu} \mathrm{dг} \mathrm{tic \& f=f} \mathrm{lse}$

[5] Guidelines on IMU use (accelerometer and gyroscopic devices) in embedded applications.

Electronic resource]: Access mode - http://www.starlino.com/imu guide.html

[6] Imar navigation company, equipment manufacturer.

Electronic resource]: Access mode -

http://www.imar-navigation.de/index.php/de/unternehmen

[7] The article "Inertial navigation - forty years of evolution". Electronic resource]: Access mode -

http://www.imar-navigation.de/downloads/papers/inertial_navigation_introduction.pdf

[8] Gura D.A., Shevchenko G.G.,Gura A.Y. Development research methodology elastic deformation total station // Journal of Engineering and Applied Sciences. 2016, Volume: 11, Issue: 13, P.:2885-2888. DOI: 10.3923/jeasci.2016.2885.2888

[9] Zheltko Ch.N., Gura D.A., Shevchenko G.G., Berdzenishvili S.G. Experimental investigations of the errors of measurements of horizontal angles by means of electronic tacheometers // Measurement Techniques. 2014. . 57. № 3. P. 277-279.

\section{How to cite this article:}

Gura D A, Shevchenko G G, Kirilchik L F, Petrenkov D V, Gura T A. Application of inertial measuring unit in air navigation for als and dap. J. Fundam. Appl. Sci., 2017, 9(1S), 732-741. 